\title{
USE OF SSR MARKERS IN IDENTIFICATION OF SUNFLOWER ISOGENIC LINES IN LATE GENERATIONS OF BACKCROSSING
}

\author{
Dimitrijević, A., Imerovski, I., Miladinović, D. ", Tančić, S., \\ Dušanić, N., Jocić, S. and Miklič, V.
}

Institute of Field and Vegetable CROPS, Oil Crops Department, Maksima Gorkog 30, 21000 Novi Sad, Serbia

Received: May 10, 2010

Accepted: October 25, 2010

SUMMARY

In the present study, thirteen SSRs (Simple Sequence Repeats) were employed for screening the level of similarity between sunflower parental lines and progeny obtained in final stages of selection. Another aim of the study was to compare the success of making isogenic lines through selection. Line $\mathrm{P}$ (donor line) was used as a donor of downy mildew gene $\mathrm{Pl}_{6}$ and backcrossed with four commercial inbred lines (A, B, C and D) susceptible to downy mildew. HAP3, a DNA-specific primer, was used to test the success of transfer of $\mathrm{Pl}_{6}$ gene from the donor line to the progeny lines in the $\mathrm{F}_{6}$ and $\mathrm{F}_{7}$ generations. It was found that all progeny lines were resistant to downy mildew. Results obtained by using thirteen primers showed that progeny lines were similar to their respective recipient parent, but further studies have to be conducted using a larger number of primers and a larger number of genotypes.

Key words: sunflower, Helianthus annuus L., isogenic line, backcross, SSR, downy mildew

\section{INTRODUCTION}

Molecular markers offer specific advantages in assessment of genetic diversity and in trait-specific crop improvement, but are also used for cultivar identification, as well as for the study of polymorphism and genetic similarity in major crops such as maize (Carvalho et al., 2004), soybean (Narvel et al., 2000), potato (Solano Solis et al., 2007), common bean (Duarte et al., 1999), sorghum (Smith et al., 2000), coconut (Perera et al., 1998) and others.

Classical backcrossing is a time-consuming process, due to the number of backcrosses needed to achieve desired results. Selection based on phenotypic char-

* Corresponding author: Phone: +381 214898 421; Fax: +381 216413 833;

e-mail: dragana.miladinovic@ifvcns.ns.ac.rs 
acteristics can be unreliable because of the environmental effects and measurement errors. By using molecular markers, required number of backcrosses can be significantly decreased, which makes their use a cost-efficient method (Knapp, 1998). Molecular markers provide an insight in the variability of the progeny at the molecular level in each generation (Moose and Mumm, 2008). The efficiency of the marker-assisted backcrossing depends on experimental design, especially on the marker density and position, population size and selection strategy (Frisch and Melchinger, 2005).

The level of polymorphism and genetic relationship have been studied by means of different molecular markers such as RAPDs (ㅁandom Amplified Polymor-

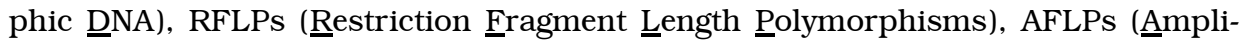
fied Fragment Length Polymorphisms) and, more recently, SSRs (Wünsch and Hormaza, 2002). Because of their multiallelic and highly polymorphic nature, microsatellite markers or SSRs are currently becoming the preferred technique for the molecular breeding in plant species. In sunflower (Helianthus annuus L.), microsatellites have been particularly useful in the studies of phylogenic relationships, genotype identification and calculation of genetic relationship between inbred lines (Smith et al., 2000; Paniego et al., 2002; Solodenko et al., 2005; Antonova et al., 2006; Hvarleva et al., 2007).

In the present study, thirteen SSRs were employed for screening the level of similarity between parental lines and their progeny obtained by selection. Line $\mathrm{P}$ (donor line) was used as a donor of $\mathrm{Pl}_{6}$ gene (downy mildew resistance gene) and crossed with four commercial lines (A, B, C and D), which are susceptible to downy mildew. The aim of this study was to check the success of backcrossing and to determine the degree of similarity of backcross progenies to both parents using SSR markers, as well as to determine if chosen SSR primers could be used for this purpose. HAP3, a DNA-specific marker, was used to determine whether $\mathrm{Pl}_{6}$ gene has been successfully transferred from the donor line to the progeny plants.

\section{MATERIALS AND METHODS}

Leaf samples were taken from original inbred lines: donor line $\mathrm{P}$ and four recipient lines: $A, B, C, D$, and their backcross progeny $A_{1-10}, B_{1-10}, C_{1-10}$ and $D_{1-10}$, respectively. Modified CTAB protocol (Permingeat et al., 1998) was used for DNA extraction.

PCR mix of $15 \mu \mathrm{l}$ contained $1 \times$ buffer, $3 \mathrm{mM} \mathrm{MgCl}_{2}, 0.2 \mathrm{mM} \mathrm{dNTP}, 0.3 \mu \mathrm{l}$ mixed primer, $1 \mathrm{U}$ enzyme, $25 \mu \mathrm{g}$ BSA, and $40 \mathrm{ng}$ DNA. The primers used for PCR amplification were: ORS 7, ORS 78, ORS 307, ORS 316, ORS 349, ORS 509, ORS 561, ORS 610, ORS 613, ORS 1079, ORS 1114, ORS 1144, ORS 1209 and HAP3. In PCR reaction with ORS primers DNA was amplified at $95^{\circ} \mathrm{C}$ for $2 \mathrm{~min}, 1$ cycle of $94^{\circ} \mathrm{C}$ of $30 \mathrm{sec}, 64^{\circ} \mathrm{C}$ for $30 \mathrm{sec}, 65^{\circ} \mathrm{C}$ for $45 \mathrm{sec}$, followed by 6 cycles in which temperature was decreased by $1^{\circ} \mathrm{C}$ per cycle, followed by 32 cycles of $94^{\circ} \mathrm{C}$ for $30 \mathrm{sec}$, $58^{\circ} \mathrm{C}$ for $30 \mathrm{sec}$, and $65^{\circ} \mathrm{C}$ for $45 \mathrm{sec}$. Final extension was at $65^{\circ} \mathrm{C}$ for $20 \mathrm{~min}$. For HAP3, PCR reaction described by Panković et al. (2007) was used. All PCR products were separated on $2 \%$ MetaPhor agarose gel. 
Genetic relationship between the parental and their progeny lines was determined by UPGMA analysis (STATISTICA 7.0; StatSoft, Inc., Tulsa, OK 74104, USA).

\section{RESULTS AND DISCUSSION}

ORS primers, being codominant, are generally used for sunflower genotyping in order to determine the genetic diversity between wild and cultivated sunflower, or sunflower lines and hybrids (Solodenko and Sivolap, 2005; Hvarleva et al., 2007). In this study we used thirteen SSR primers, created by Tang et al. (2002) for testing sunflower isogenic lines in final stages of selection, in order to determine the degree of similarity between the parental lines and their $\mathrm{F}_{6}$ and $\mathrm{F}_{7}$ progeny lines. Eight primers showed presence of polymorphism between parental lines. ORS 509, ORS 610 and ORS 1209 primers amplified multiple bands and thus proved to be the most informative of all primers used in genotyping of the $F_{6}$ and $F_{7}$ generations of progeny lines and their parental lines (Table 1). ORS 509 amplified the largest number of bands of all primers used (five in total). In the work of Solodenko and Sivolap (2005), ORS 509 amplified only three bands in all of the investigated inbred lines. Two out of the five bands on PCR profiles of inbred lines in our experiment were of the same size as the bands obtained by Solodenko and Sivolap (2005). The DNA fragment length in the SSR profiles of the tested inbreds varied from 184-202 bp.

Table 1: Genetic profile of parental and progeny lines obtained by amplification with 13 ORS primers in the $\mathrm{F}_{6}$ and $\mathrm{F}_{7}$ generation of backcrossing.

\begin{tabular}{lccccccccc}
\hline & $\mathrm{P}$ & $\mathrm{A}$ & $\mathrm{B}$ & $\mathrm{C}$ & $\mathrm{D}$ & $\mathrm{A}_{1-10}$ & $\mathrm{~B}_{1-10}$ & $\mathrm{C}_{1-10}$ & $\mathrm{D}_{1-10}$ \\
\hline ORS 7 & 272 & 272 & 272 & 272 & 272 & 272 & 272 & 272 & 272 \\
ORS 78 & 165 & 165 & 165 & 165 & 165 & 165 & 165 & 165 & 165 \\
ORS 307 & 118 & 118 & 150 & 193 & 118 & 118 & 150 & 193 & 118 \\
ORS 316 & 202 & 202 & 195 & 202 & 202 & 202 & 195 & 202 & 202 \\
ORS 349 & 254 & 254 & 254 & 254 & 254 & 254 & 254 & 254 & 254 \\
\hline & 81 & 81 & 81 & 81 & 81 & 81 & 81 & 81 & 81 \\
ORS 509 & 120 & 120 & 120 & 120 & 120 & 120 & 120 & 120 & 120 \\
& 202 & 202 & 183 & 183 & 183 & 202 & 183 & 183 & 183 \\
& & & 194 & & & & 194 & & \\
\hline \multirow{2}{*}{ ORS 561 } & 373 & 373 & 373 & 400 & 400 & 373 & 373 & 400 & 400 \\
& & & 400 & & & & 400 & & \\
\hline \multirow{2}{*}{ ORS 610 } & 168 & 178 & 178 & 178 & 178 & 178 & 178 & 178 & 178 \\
& 232 & 232 & 232 & 232 & 232 & 232 & 232 & 232 & 232 \\
\hline ORS 613 & 313 & 313 & 313 & 313 & 313 & 313 & 313 & 313 & 313 \\
ORS 1079 & 239 & 239 & 239 & 239 & 239 & 239 & 239 & 239 & 239 \\
ORS 1114 & 252 & 402 & 360 & 402 & 374 & 402 & 360 & 402 & 374 \\
ORS 1144 & 181 & 280 & 269 & 252 & 269 & 280 & 269 & 252 & 269 \\
\hline \multirow{2}{*}{ ORS 1209 } & 328 & 328 & 178 & 202 & 178 & 181 & 178 & 202 & 178 \\
\hline & 512 & 512 & 512 & 512 & 512 & 512 & 512 & 512 & 512 \\
& 643 & 643 & 643 & 643 & 643 & 643 & 643 & 643 & 643 \\
\hline
\end{tabular}


PCR profiles obtained from ORS 509 and ORS 1209 showed that progeny lines $\mathrm{B}_{1-10}$ and $\mathrm{D}_{1-10}$ in the $\mathrm{F}_{6}$ generation were not completely identical with their respective recipient parent. ORS 509 and ORS 1209 amplified some non-specific bands, in most of the progeny plants of back crosses with the line $\mathrm{B}\left(\mathrm{B}_{1-10}\right)$ and the line $\mathrm{D}$ $\left(D_{1-10}\right)$. In the $F_{7}$ generation in all progeny lines of line $D$, ORS 509 amplified the same bands as in recipient line (D). In the progenies of line $B$ the same primer amplified some, bands originating from donor line (P). Non-specific bands were not amplified. ORS 1209 amplified four bands of the same size in all parental and progeny lines. Although ORS 610 amplified three bands in the work of Hvarleva et al. (2007), in our study this primer amplified four bands in all parental lines and $\mathrm{F}_{6}$ progeny lines, so there was no need to use this primer in the analysis of the next generation.

Primers ORS 307, ORS 1079, ORS 1114, and ORS 1144 were also highly informative in our study, amplifying three bands. In the work of Tang and Knapp (2003) and Zhang et al. (2005) the same number of bands in elite inbred lines was amplified by using ORS 307, while in the work of Hvarleva et al. (2007) this primer amplified two bands. ORS 1144 amplified seven bands in wild and domesticated sunflower species and two in inbred lines (Solodenko and Sivolap, 2005).

In progeny lines $\mathrm{B}_{1-10}$ and $\mathrm{D}_{1-10}$, in the $\mathrm{F}_{6}$ generation, bands that belonged to both parental lines were amplified by ORS 1079 (Figure 1), therefore, this primer was used to test the degree of similarity of progeny lines with their maternal line in the next generation of selection.

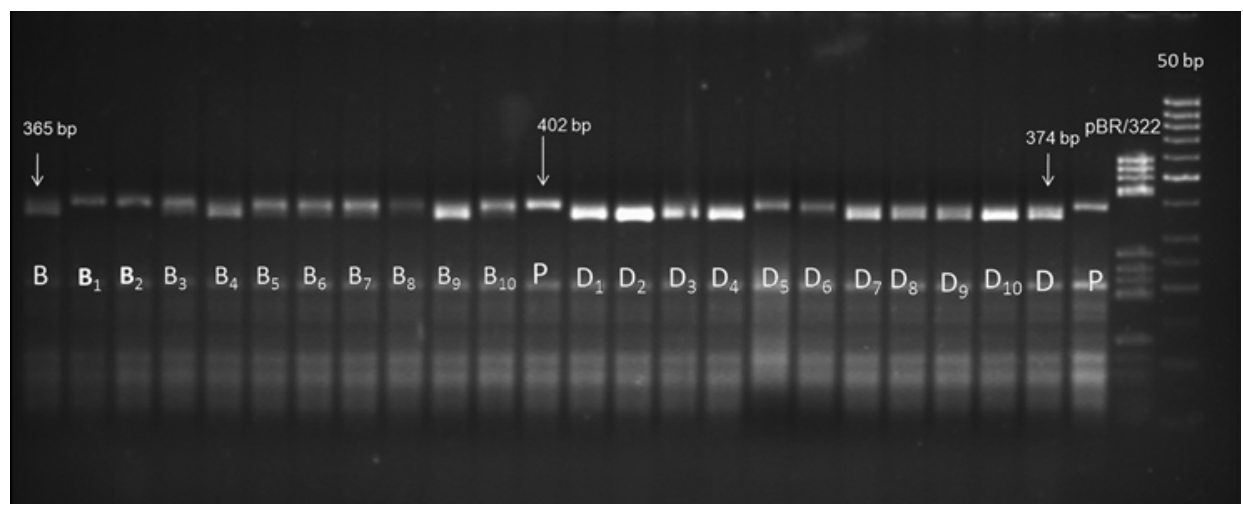

Figure 1: PCR amplification profile of parental lines ( $B$ and $D$ ) and their respective progeny lines from crosses with line $P\left(B_{1-10}\right.$ and $\left.D_{1-10}\right)$ (the $F_{6}$ generation) obtained with ORS 1079 primer.

ORS 1079 showed that progeny of line $\mathrm{D}\left(\mathrm{D}_{1-10}\right.$, the $\mathrm{F}_{7}$ generation) was genetically identical to this line, while only one progeny plant, $\mathrm{B}_{5}$, was genetically identical with its recipient line $B$, two progeny plants, $B_{2}$ and $B_{7}$, were identical with the donor line $(\mathrm{P})$ and the rest of the progeny plants had bands from both parents (Figure 2). 
In our experiment, ORS 316 and ORS 561 amplified two allele combinations. These primers amplified three and five alleles in sunflower elite inbred lines, respectively (Tang and Knapp, 2003). ORS 561 amplified some non-specific bands or bands that originated from both parental lines, $B$ and $P$, in $F_{6}$ and $F_{7}$ progeny genotypes of $\mathrm{B}_{1-10}$.

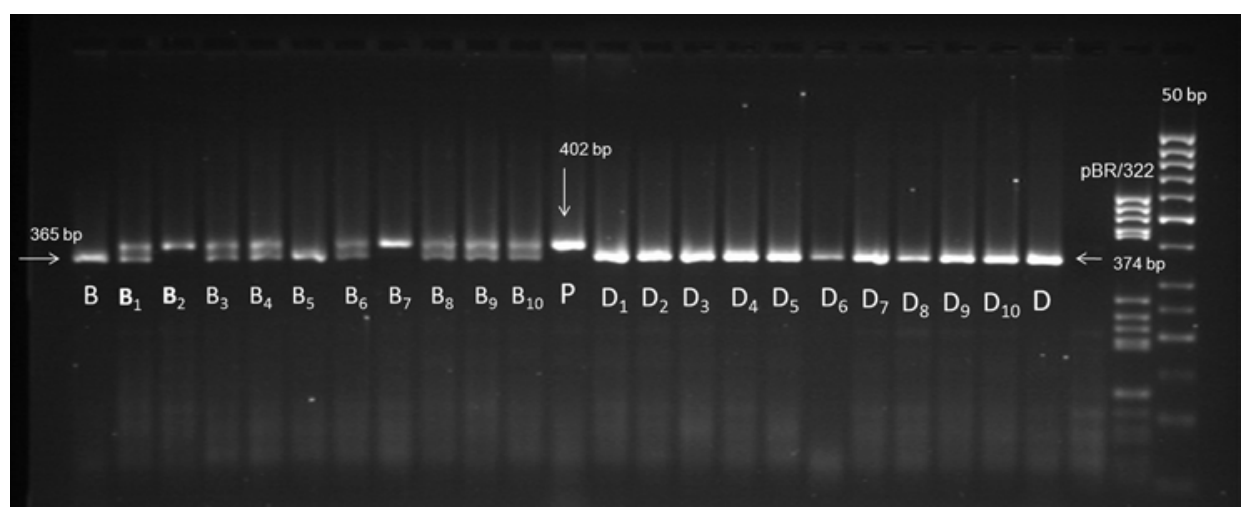

Figure 2: PCR amplification profile of parental lines ( $B$ and $D$ ) and their respective progeny lines from crosses with line $P\left(B_{1-10}\right.$ and $\left.D_{1-10}\right)$ (the $F_{7}$ generation) obtained with ORS 1079 primer.

ORS 7 and ORS 78 amplified only one band in the tested inbred lines and their progenies. This is not in agreement with the results of Haverleva et al. (2007) and Solodenko and Sivolap (2005) who found these markers to be polymorphic, amplifying two and three bands, respectively. ORS 78 amplified a band of the same size as in the work of Solodenko and Sivolap (2005). Beside ORS 7 and ORS 78, ORS 349 and ORS 613 also did not appear to be reliable markers for further research because of their monomorphic nature. Tang and Knapp (2003) found ORS 349 to be monomorphic for elite inbred lines, but polymorphic for exotic domesticated and wild sunflower populations.

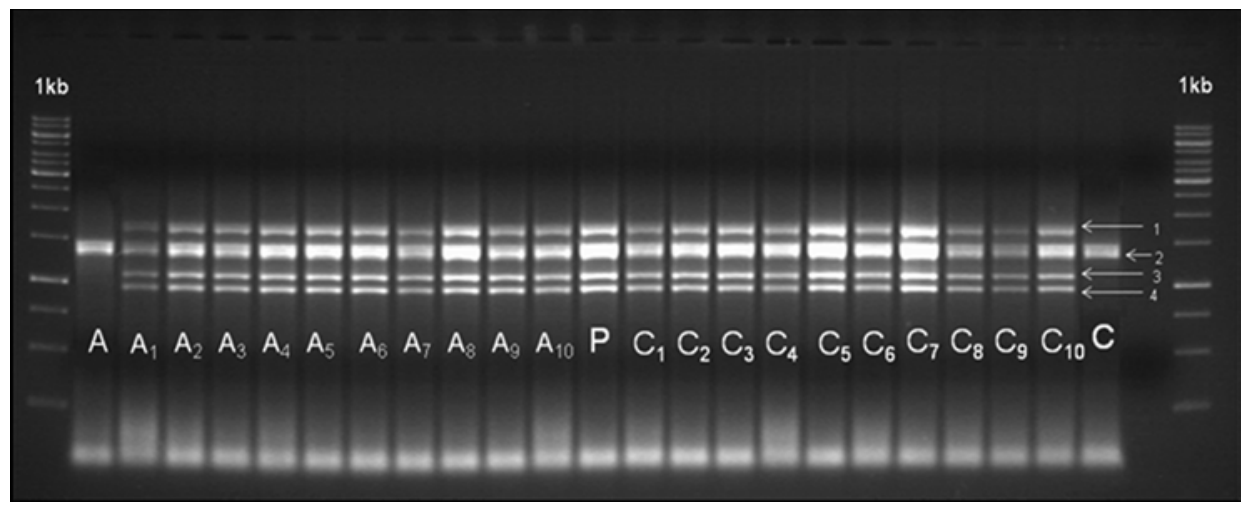

Figure 3: HAP3 primer amplified 4 bands (1. $1720 \mathrm{bp}, 2.1330 \mathrm{bp}, 3.1060 \mathrm{bp}, 4.940 \mathrm{bp}$ ) in resistant $P$ and all progeny plants $A_{1-10}$ and $C_{1-10}$ (the $F_{7}$ generation), and one band in susceptible recipient lines $A$ and $C$. 
HAP3 was chosen for its specific use in detecting the presence of $\mathrm{Pl}_{6}$, a downy mildew resistance gene (Panković et al., 2007). HAP3 primer amplified 4 bands ( $1720 \mathrm{bp}, 1330 \mathrm{bp}, 1060 \mathrm{bp}$ and $940 \mathrm{bp}$ ) in donor line $\mathrm{P}$ and all progeny lines in the $\mathrm{F}_{6}$ and $\mathrm{F}_{7}$ generations, and one band ( $1330 \mathrm{bp}$ ) in recipient lines $\mathrm{A}, \mathrm{B}, \mathrm{C}$ and $\mathrm{D}$, confirming that downy mildew resistance gene has been successfully transferred from line $\mathrm{P}$ to all progeny lines (Figure 3 ).

Bands generated in $F_{7}$ progenies and parental lines using all thirteen ORS primers and HAP3 primer were analyzed by assigning 1 or 0 depending on the presence or absence of each allele form. The dendrogram showed that there was a great

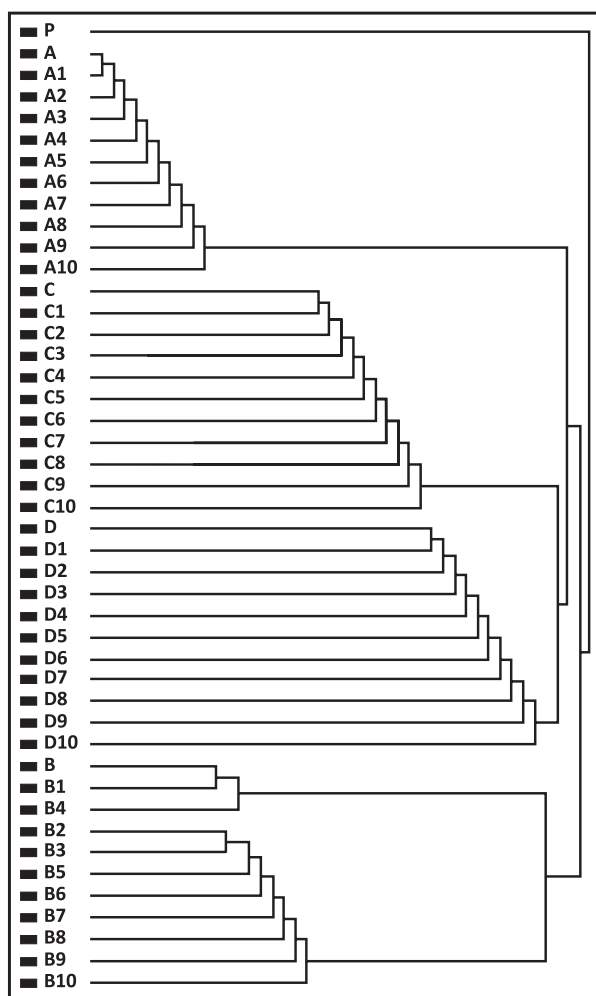

Figure 4. Dendrogram based on SSR data of parental and progeny lines difference between parental line $\mathrm{P}$ (donor line) and recipient lines $\mathrm{A}, \mathrm{B}, \mathrm{C}$ and $\mathrm{D}$ (Figure 4).

All progeny lines showed the highest similarity to their recipient parental line (e.g., $\mathrm{A}_{1}$ to $\mathrm{A}_{10}$ belong to the same subcluster as their recipient line $\mathrm{A}$, etc.). However, due to the presence of bands that originated from both parental lines in $\mathrm{F}_{7}$ progeny lines $\mathrm{B}_{1-10}$, there was an additional sub-cluster formed in B sub-cluster. Consequently, an additional backcross should be carried out in order to create a population that will be genetically close (preferably identical) to its maternal line, and still be resistant to downy mildew. An improvement in the level of similarity between progeny lines $\mathrm{D}_{1-10}$ and line D was shown, as all progeny lines showed the same profile as their recipient line, after electrophoresis.

\section{CONCLUSIONS}

Progeny lines formed clusters with their respective recipient line, while line $P$ formed a separate cluster. This shows that the combination of primers used in this study is sufficiently informative. ORS 509, ORS 610 and ORS 1209 proved to be the most informative primers, because they amplified bands that differed between recipient lines and donor line $\mathrm{P}$, thus clearly distinguishing these lines. Besides ORS 509 and 1209, ORS 1079 amplified bands that belonged to both parental lines in some individual plants of $\mathrm{B}_{1-10}$ and $\mathrm{D}_{1-10}$ in $\mathrm{F}_{6}$ generation. All $\mathrm{F}_{7}$ progeny lines $\mathrm{D}_{1-10}$ had the same profile as their recipient line $\mathrm{D}$, but there were still some plants 
in $\mathrm{F}_{7}$ generation of $\mathrm{B}_{1-10}$ that did not show the same profile as their recipient line $\mathrm{B}$. These results showed that an additional backcross should be carried out. Downy mildew resistance gene $\mathrm{Pl}_{6}$ was successfully transferred to all progeny plants. The results obtained by using thirteen ORS primers showed that progeny lines are similar to their respective recipient line, but further studies are needed which would include new primers on greater number of genotypes.

\title{
ACKNOWLEDGEMENT
}

\author{
This work was supported by the Ministry of Science and Technological \\ Development, Republic of Serbia, project TR 20080.
}

\section{REFERENCES}

Antonova, T.S., Guchetl, S.Z., Tchelustnikova, T.A. and Ramasanova, S.A., 2006. Development of marker system for identification and certification of sunflower lines and hybrids on the basis of SSR-analysis. Helia 29(45): 63-72.

Carvalho, V.P., Ruas, C.F., Ferreira, J.M., Moreira, R.M.P. and Ruas, P.M., 2004. Genetic diversity among maize (Zea mays L.) landraces assessed by RAPD markers. Genetics and Molecular Biology 27(2): 228-236.

Duarte, J.M., Bosco dos Santos, J. and Cunha Melo, L., 1999. Comparison of similarity coefficients based on RAPD markers in the common bean. Genetics and Molecular Biology 22(3): 427-432.

Frisch, M. and Melchinger, A.E., 2005. Selection theory for marker-assisted backcrossing genetics. Genetics 170: 909-917.

Hvarleva, Tz., Bakalova, A., Chepinski, I., Hristova-Cherbadji, M. and Hristov, M. and Atanasov, A., 2007. Characterization of Bulgarian sunflower cultivars and inbred lines with microsatellite markers. Biotechnology \& Biotechnological Equipment 21(4): 408-412.

Knapp, S.J., 1998. Marker-assisted selection as a strategy for increasing the probability of selecting superior genotypes. Crop Sci. 38:1164-1174.

Moose, S.P. and Mumm, R.H., 2008. Molecular plant breeding as the foundation for $21^{\text {st }}$ century crop improvement. Plant Physiology 147: 969-977.

Narvel, J.M., Fehr, W.R., Chu, W., Grant, D. and Shoemaker, R.C., 2000. Simple sequence repeat diversity among soybean plant introductions and elite Genotypes. Crop Sci. 40: $1452-1458$.

Paniego, N., Eschaide, M., Munoz, M., Fernandez, L., Torales, S., Faccoi, P., Fuxan, I., Carrera, M., Zandomeny, R., Suarez, E. and Hopp, H., 2002. Microsatellite isolation and characterization in sunflower (Helianthus annuus L.). Genome 45: 34-43.

Panković, D., Radovanović, N., Jocić, S., Satović, Z. and Škorić, D., 2007. Development of codominant amplified polymorphic sequence markers for resistance of sunflower to downy mildew race 730. Plant Breeding 126(4): 440-444.

Perera, L., Russell, J.R., Provan, J., McNicol, J.W. and Powell, W., 1998. Evaluating genetic relationships between indigenous coconut (Cocos nucifera L.) accessions from Sri Lanka by means of AFLP profiling. Theor. Appl. Genet. 96: 545-550.

Permingeat, H.R., Romagnoli, M.V. and Vallejos, R.H., 1998. A simple method for isolating high yield and quality DNA from cotton (Gossypium hirsutum L.) leaves. Plant Mol. Biol. Rep. 16: 1-6.

Smith, J.S.C., Kresovich, S., Hopkins, M.S., Mitchell, S.E., Dean, R.E., Woodman, W.L., Lee, M. and Porter, K., 2000. Genetic diversity among elite sorghum inbred lines assessed with simple sequence repeats. Crop Sci. 40: 226-232.

Solano Solis, J., Morales Ulloa, D. and Anabalón Rodríguez, L., 2007. Molecular description and similarity relationships among native germplasm potatoes (Solanum tuberosum ssp. tuberosum L.) using morphological data and AFLP markers. Electron. J. Biotechnol. [online]. 10(3): 436-443. ISSN 0717-3458. 
Solodenko, A. and Sivolap, Y., 2005. Genotyping of Helianthus based on microsatellite sequences. Helia 28(42): 19-26.

Tang, S. and Knapp, S.J., 2003. Microsatellites uncover extraordinary diversity in native American land races and wild populations of cultivated sunflower. Theor. Appl. Genet. 106(6): 990-1003.

Tang, S., Kishore, V.K. and Knapp, S.J., 2003. PCR-multiplex for a genome-wide framework of simple sequence repeat marker loci in cultivated sunflower. Theor. Appl. Genet. 107(1): 6-19.

Tang, S., Yu, J.-K., Slabaugh, M., Shintani, D., and Knapp, S., 2002. Simple Sequence Repeat Map of the Sunflower Genome. Theor. Appl. Genet. 105(8): 1124-1136.

Wünsch, A. and Hormaza, J.I., 2002. Cultivar identification and genetic fingerprinting of temperate fruit tree species using DNA markers. Euphytica 125: 59-67.

Zhang, L.S., Le Clerc, V., Li, S. and Zhang, D., 2005. Establishment of an effective set of simple sequence repeat markers for sunflower variety identification and diversity assessment. Can. J. Bot. 83(1): 66-72. 